\title{
Lifelong Learning in Social Work: A Qualitative Exploration with Social Work Practitioners, Students, and Field Instructors
}

\author{
Pauline Jivanjee \\ Kimberly Pendell \\ Laura Nissen \\ Charlotte Goodluck
}

\begin{abstract}
In the context of rapid change in social work practice related to policy, research findings, and theoretical developments, faculty are challenged to prepare students to engage in lifelong learning, a concept that has not been well-articulated in social work education. This article reports on an exploratory study of students,' social workers,' and field instructors' perspectives and experiences of lifelong learning. Based on focus group discussions, findings reveal the multi-faceted nature of lifelong learning, the personal characteristics and motivations of lifelong learners, and the roles of social work faculty and workplace environments in supporting learning. Implications address the roles of instructors and social work programs in giving students and social workers tools and opportunities to engage in continuous learning and professional growth.
\end{abstract}

Keywords: Social work education, workplace, lifelong learning, motivation

Social work practice occurs in the context of rapidly changing community needs and policies, as well as new research findings and theoretical developments. Lifelong learning enables social workers to continually update their knowledge and skills in order to provide relevant and effective services. Social workers encounter ongoing expectations to serve new populations experiencing emerging social problems. At the same time, they experience pressures to engage in evidence-based and culturally-responsive practices, and are required to be accountable for outcomes in environments of shrinking public resources. Therefore, it is essential for social workers to be lifelong learners. The Council on Social Work Education (CSWE) has recognized this need. The 2015 CSWE standards include the statement, "Social workers recognize the importance of lifelong learning and are committed to continually updating their skills to ensure they are relevant and effective" (CSWE, 2014, p. 3). Lifelong learning in social work addresses the continuous learning and transformation needed to be an effective social worker in the changing social, economic, and political environment. However, there is little research on lifelong learning in social work and few guidelines about how lifelong learning is viewed or embraced by social workers or social work students.

As social work education has shifted from using a knowledge-based curriculum structure to a competency-based structure (Petracchi \& Zastrow, 2010a; 2010b), the CSWE adopted Educational Policy Assessment Standards (EPAS) to assess the competencies believed to be necessary for effective social work practice. These standards include an expectation that students begin their professional lives recognizing that they will need to renew their knowledge and skills continually. Definitions of lifelong learning reflect this

\footnotetext{
Pauline Jivanjee is an associate professor at Portland State University’s School of Social Work. Kimberly Pendell is an assistant professor at the Portland State University Library. Laura Nissen is the dean and a professor at Portland State University’s School of Social Work. Charlotte Goodluck (deceased) was a professor at Portland State University’s School of Social Work. 
explicit link with performance on the job. For example, the Professional Association Research Network articulated lifelong learning as “... the purposive maintenance, improvement and broadening of your knowledge, skills and personal qualities in order to perform your professional activities successfully throughout your working life” (as cited in Frost, 2001, p. 12). Gustavsson (2002) connects lifelong learning with the personal qualities needed for effective professional performance: “...what counts is flexibility, sensitivity, and openness to the world” (p. 22). These definitions are useful as a foundation for considering how social workers engage in lifelong learning and how educators and others can best promote and facilitate lifelong learning.

Nissen, Pendell, Jivanjee, and Goodluck (2014) described the varied emphases in definitions of lifelong learning for social work. For example, lifelong learning has been defined as intentional learning that people engage in throughout their lives for personal and professional fulfillment (Dunlap \& Grabinger, 2003), a socio-personal process (Billet, 2010), a self-directed process (Bolhuis, 2003), and a reflective process (Frost, 2001). According to Daley (2001), social workers described continuing education as a meaningmaking process and reported using it to gain new information to advocate for clients and to create renewed momentum and inspiration in their work. Cournoyer and Stanley (2002) offer what appears to be the most comprehensive definition:

Lifelong learning for social work refers to ongoing processes associated with the acquisition or construction of information, knowledge, and understanding; the development, adoption, and reconsideration of values and attitudes; and the development of skills and expertise... from the time someone first explores social work as an educational or professional career choice to the time that person no longer considers him- or herself a social worker. (p. 4)

Social work literature addresses aspects of the learning needed for contemporary social work practice but to date, there has been little attention as to how social workers engage as lifelong learners throughout their professional lives. Licensed social workers are required to participate in continuing education to maintain their licensure (Nissen et al, 2014) and some studies examined how social workers gain and apply new information immediately following their participation in continuing education offerings, for example, trainings on evidence-based practices (Gira, Kessler, \& Poertner, 2004; Wharton \& Bolland, 2012). An exploratory study reported positive outcomes of continuing education on social workers' understanding of and use of evidence-based practices (Parrish \& Rubin, 2011). Other studies have examined the effects of continuing education on improving social workers' knowledge and skills. For example, Smith and colleagues (2006) showed that higher motivational orientation toward professional knowledge was associated with selfperceived changes in knowledge, attitudes, and behavior of social workers. Lam and colleagues (2006) demonstrated that problem-based learning boosted social work students' ownership of self-directed learning at the end of their formal training. Following a comparative study of learning across professions, Daley (2001) reported that to make new knowledge meaningful, participants integrated it with previous professional experience "in a recursive, transforming process" (p. 50). In the same study, Daley also found social workers motivated to seek new information to improve their support and advocacy on 
behalf of clients as well as gaining renewed inspiration and commitment to their profession following continuing education.

Assessment of the content and nature of lifelong learning among social workers has been limited to date. Returning to Cournoyer and Stanley (2002), the authors reported on the development of an instrument to measure lifelong learning in social work including seven dimensions: regular review of professional literature; enjoyment of learning; regular pursuit of learning activities and opportunities; openness to feedback from others that learning may be needed; knowledge of one's personal learning style and preferences; active engagement with, and responsibility for one's own learning plan; and enjoyment of teaching others. However, this scale has not been used in additional research or program development in schools of social work or practice settings (Cournoyer, Professor, February 22, 2014, personal communication).

In summary, the literature on lifelong learning provides little information on social workers' motivation toward lifelong learning, how they engage with and apply new learning, and what supports they might need. This exploratory study addresses the identified gap in the literature by examining the perspectives and attitudes of social workers, field instructors, and social work students regarding lifelong learning. The study was designed with guiding research questions derived from a review and synthesis of existing literature (Nissen et al., 2014): What does lifelong learning mean to social workers, field instructors, and social work students? What is the role of a school of social work in promoting lifelong learning? What factors are reported to support or impede lifelong learning in social work practice settings? What kinds of information and experiences contribute to lifelong learning in social work?

Observing the limited literature focused on this topic, a research team of three social work faculty members and the University's social work librarian sought to better understand lifelong learning in social work, and the roles of social workers, social work educators, supervisors, and students related to lifelong learning. By eliciting the perspectives of current students, as well as social workers in the community, the study aimed to promote understanding of what motivates students and social workers to learn, and thereby provide useful information for social work educators, field instructors, professional leaders, and social work practitioners to enhance social work's relevance and effectiveness in meeting community needs.

\section{Methods}

This exploratory qualitative study employed focus groups of BSW students, MSW students, alumni/practitioners, and field instructors to investigate perceptions of lifelong learning in social work. Focus groups were selected as the medium for data collection to elicit participants' attitudes and frameworks for understanding their experiences (Kitzinger, 1994). To enhance the trustworthiness of the findings, the researchers followed recommended strategies for focus group inquiry (Creswell, 2013; Padgett, 2008; Polkinghorne, 2007). The University’s Institutional Review Board approved the study. 


\section{Participants}

Using email listservs and social networks, researchers recruited a convenience sample of BSW and MSW students, social work alumni/practitioners, and field instructors associated with one university to participate in focus groups for this exploratory study. Separate focus groups were held for all four participant types. Social work faculty members were also interviewed; however, due to the significant difference in the interview protocol for faculty and the different emphases in their responses, their responses will be reported in a separate article. Potential participants volunteered using an online form. When a sufficient number (5-7) of participants had volunteered, the groups were scheduled. Email reminders were sent to participants the day prior to their focus group.

Due to absences, a total of 13 volunteers participated in four focus groups: two BSW students, five MSW students, two alumni who worked as social work practitioners, and four field instructors who were engaged in agency-based social work practice as well as supervising students. While the researchers had hoped for larger groups, the smaller focus groups proceeded to respect the time of participants who had attended. The discussions with pairs of participants proved to be extremely rich. Ten participants were females and three were males. Participants indicated their age in categories: 18-24, 25-34, 35-44, and 45 years old and above. Each age group was represented in the focus groups overall, with the majority of participants being 35 years old and above. One participant identified herself as Mexican-American; the remaining participants identified as either white or did not identify their ethnicity. Two participants indicated gay or queer sexual orientation. One participant noted the presence of a disability. None of the student participants were currently taking classes with the researchers conducting the study, although some had taken classes with one faculty researcher in the past.

\section{Procedure}

Separate focus groups were facilitated by two team members, one of whom took the role of lead facilitator while the other managed logistics and asked clarifying questions. Before beginning the focus group discussion, each participant reviewed and signed an informed consent. Focus groups ranged from 60 to 90 minutes. Focus group discussions were audio-recorded and were subsequently transcribed for analysis by the researchers.

The questions asked in the focus groups were similar, but students were asked one additional question and alumni/practitioners and field instructors were asked a few different questions to address their professional perspectives. All groups opened with an icebreaker question about the participants' most passionate areas of social. Subsequent questions focused on the types and sources of information they need for social work practice, how they use information, and how they deal with challenges in trying to find or use new information. Another set of questions inquired about what participants do when faced with a professional situation they do not feel prepared for, what motivates them to learn, how they define lifelong learning, and what would help them to become lifelong learners. For students, a closing question asked for their opinion on what other questions related to the topics of information and lifelong learning the social work profession should be asking. Additional questions asked of alumni/practitioners and field instructors were: Do you note 
any changing trends in the kinds, types, or forms of information you use or will use as a social worker? Has your definition of lifelong learning changed since you left school? How do you stay engaged in your practice and profession? Describe the organizational culture that you work in with regard to capacity and practices for the flow of new information, methods, or ideas into social work practice. Near the end of each focus group we paused to invite participants to share ideas related to what had been discussed already, a form of member checking.

All four researchers participated in collaborative data analysis guided by the constant comparison approach of Glaser and Strauss (1967) as modified by Charmaz (2005) and Morse (1994). Following each focus group, each pair of team members met to debrief and identify major areas of themes. After transcription, each member read all the transcripts independently and noted key themes and categories in content related to aspects of lifelong learning in social work, using the major topics to guide the preliminary analysis. Within these broad categories, team members identified themes and categories in an inductive analysis process. Team members subsequently held a series of meetings to describe and explain our rationales for assigning specific categories and selecting exemplary quotes that illustrated them. This process resulted in a set of consensus-determined categories and themes and a preliminary code list. Individual members then took responsibility for analyzing the data linked to one or two major themes across all focus groups and shared this analysis with other members, followed by additional meetings in which each member responded to questions about their analysis and made changes, resulting in team agreement on the final analysis.

\section{Findings}

Researchers explored four topics: participants' definitions of lifelong learning; information access and processing; the role of schools of social work in promoting lifelong learning; and lifelong learning in the workplace environment. The following summarizes each topic explored in the focus groups and the themes that emerged through narrative analysis. Participant quotes inform and illustrate each theme.

\section{What is Lifelong Learning?}

During the focus group process, all informants were asked to define lifelong learning as they currently conceptualize it. Although the concepts they described varied, their comments reflected a few core ideas: personal commitment to learning; humility as a guiding perspective; and differentiating knowing and doing. The definitions focus group members offered were a fluid combination of personal qualities and attitudes, such as openness and engagement.

Overall, participants appeared to be familiar and engaged with the concept of lifelong learning and aware of its importance to their education and practice, which may have been expected since the participants were self-selected. They spoke enthusiastically about the idea of lifelong learning, and described lifelong learning as a personal characteristic as opposed to an external, premeditated action: "I just love being around new knowledge and hearing people talk about things" (social worker) and "I think for me learning is easy, 
learning is a way of life. It is who I am. It is part of my identity” (MSW student). A key element of lifelong learning appeared to be related to the affective aspects of the learning process. Participants noted a variety of positive motivations for their involvement in lifelong learning such as being excited, eager, engaged, and curious.

Participants emphasized the need for personal commitment and taking responsibility for lifelong learning. In relationship to lifelong learning, both BSW and MSW students reported a sense of dissatisfaction with current beliefs and a commitment to challenging oneself: "I think it is a commitment to not being satisfied with what you believe...lifelong learning is a commitment that you are not going to allow those easy thought patterns to be your only thought patterns" (BSW student); and "[lifelong learning] is being engaged and continuing to be curious and to push myself out of my comfort zone” (MSW student).

In focus group discussions, humility surfaced as a guiding stance or quality needed for lifelong learning. An MSW student described learning as, “...just curiosity with humility and openness to learning." Participants implied that humility is closely tied to the qualities of curiosity and openness, reflecting the idea that — even with the best of intentions-one must have the willingness to take chances that may result in mistakes. These mistakes will, in turn, inform ongoing learning:

Lifelong learning is really having the ability to be open to new ideas, different ways of thinking, whatever it may be, just being open to that... You have to remain a bit humble...that reserved piece of just saying 'tell me more...' (field instructor)

Another field instructor also commented on the humility and openness required for lifelong learning, defining a lifelong learner as a person who is: "willing to try new things, willing to look at new things, willing to try new ways of doing business, willing to ask questions, willing to take risks...[and] also willing to make mistakes." Participants described social work practice as a larger commitment to ongoing learning extending over one's life. Acceptance, and even delight, could be found in this aspect of learning: "I know less now than when I began. I don't mean that in a bad way. I mean that lifelong learning is exactly what it means. There is no plateau here and there never, ever will be" (alumnus/practitioner).

Respondents differentiated "knowing things" from applying information; they emphasized the roles of integration and application in lifelong learning. For example, an MSW student noted:

I could read a million books, but I think it is integration that makes it learning. It is the how I am using it? How I am applying it? How I am working, how it is changing me and the way that I work, that makes it learning, instead of knowledge.

Participants described different motivations for their desire to gain skills needed for social work, which were linked with their curiosity, social connections, and fear or shame about not knowing. Numerous respondents described motivations guiding the ways they defined and thought about lifelong learning such as the realization that knowledge is continually evolving, and that professional effectiveness is linked to ongoing professional development. For example, one field instructor shared: 
Part of wanting to be a strong practitioner is being open to the fact that there is so much I don't know. That kind of drives my interest; particularly in a field where social justice is part of our core values. That's so dynamic. It's going to involve needing to continue to learn.

Participants described lifelong learning as their commitment to the processes of engagement and change, and a sense of power in learning about new topics and having access to resources that provide them with knowledge and competencies for social work.

Lifelong learning as a form of social connection also surfaced in the focus groups. Several participants described how they created new and strong connections to others through learning. For example, a BSW student addressed the benefits of learning for relationship-building: "I like to be able to connect with people and I feel learning about them makes it easier. I think the promise of being able to connect with people better is kind of my reward for learning." This theme also touches upon the sharing of information as a way of building a professional social network. Social work students and practitioners reported that they strategically build professional and social networks in order to discover, share, and discuss new information. Students referred to the importance of fellow students, researchers, and practitioners as vital sources of information. Information acts as a starting point for relationships, a catalyst for social and professional networks that then form a strong basis for ongoing learning. An MSW student commented:

I just flail, so oftentimes I end up Googling and looking at scholarly research, which is so not enough. We need to really know and have an internalized level of how to find information and find alliances and kinships and other like-minded people who can help us continue in our work as we move into the world.

Another student offered: "Sometimes using that information [regarding social justice] to ask questions to strategic people and build strategic relationships has been a big thing for me” (MSW student).

Less positive motivations also emerged, such as shame or feeling apologetic in regards to not knowing or feeling safe with not knowing. A BSW student posited:

I think safety [is important] because sometimes when you don't know something you are kind of shamed by it. I feel like that when my career kind of develops, I am going to be hesitant to allow other people to know that I don't know about this. I think there is kind of a shame in that, like you should know about this.

An MSW student admitted, "I didn't want to admit to the group that I was totally incompetent."

\section{Information Access and Processing}

In response to an exploratory question, participants talked at length about how they discover and use new information and research in their academic and professional work. While social work journals and other scholarly publications were frequently cited as sources of information for their work, participants also discussed the importance of continued access to research literature; how they build networks for sharing information 
among colleagues and mentors; the value of alternative information sources; and how they evaluated and applied new learning.

Continuing access to current research was reported as an ongoing concern for social work practitioners in the community and as a future concern for students. Students predicted accurately that their access to journal articles would significantly change or even disappear upon leaving the university. An MSW student lamented their future loss of access to scholarly journals:

I love libraries, but I know that my access to this library in particular is going to be next to nil once I graduate... There isn't much out there for those of us that like research and want to base it [practice] on research. We are a little bit in a hole.

Alumni/practitioners and field instructors expressed appreciation for workplaces that provide access to relevant academic journals. Field instructors also cited the benefit of their affiliation with the University, which provides off-site library access to academic journals that would not otherwise be available to them.

Social work students and practitioners reported that they seek out a variety of information sources. Scholarly research is valued, but information from sources outside the traditional and dominant discourse is also sought and incorporated into practice:

I definitely would start with a lot of journals, but then also I feel that because the population that I'm most interested in, there is not a lot written about them. Because they can be so small, I look for a lot of blogs and more nontraditional sources of information....It is usually research by white folks or analysis by white folks, so it is always interesting to find perspectives on it from the communities that it is affecting the most. (alumnus/practitioner)

Students and practitioners consistently demonstrated their awareness and concern that scholarly research did not present a full enough picture of a social problem or situation to apply to their practice, and they also sought information from community informants.

Focus group participants described using new information as a process that involves balancing sources, reflection, building the context or macro view, and understanding the information's impact on practice. Responses from participants formed a continuum of steps from receiving new information to shaping new learning and practice, using phrases such as: rehearse, reflect, discuss, dialog, test, and evaluate. For example, one MSW student described his imaginative process of taking new information and constructing a new scenario based on a previous experience: "I think just like rehearsing information learned, thinking back to past situations and how I would have acted differently if I had known and then preparing for the future if I run into the same situation.”

\section{The Role of Social Work Education in Lifelong Learning}

While participants reported a lifelong learning disposition before entering their social work program, they also expressed appreciation for the lifelong learning foundation built during their program and the inspiring influence of faculty members. An alumnus/practitioner commented, "I wouldn't be as successful as I have been in this program if it wasn't for the foundations you gave me... it is up to me to do the rest." Another 
alumnus/practitioner described learning a critical perspective as a foundation for future learning:

The school does such a good job of embedding that in you, it really allows you to grow and flourish kind of naturally without even having to think about it... it is kind of implicit... the degree has really helped me to continue to want to learn and be inspired.

Some faculty members were reported to be particularly effective in promoting lifelong learning. For example, a few participants commented on a specific faculty member who had "reinforced" lifelong learning by being so "passionate about it" and "instilled as a thing that you are just going to continue to do and it is your responsibility to do it." An MSW student commented on the importance of faculty members modeling lifelong learning:

When you see people who have been in the field for a long time or whatever and they know the latest stuff and they are able to throw it out and engage people, young people, that is exciting to me... just seeing it in them inspires it even further to me.

Returning to the importance of feeling safe in the learning process, a student participant added, "I think that is perfect when they are like, you know, 'I don't know it all yet, either,' and that's okay and it is safe not to know it." Another MSW student commented that instructors promote lifelong learning when they "share their passions in the classroom" and especially when they create a learning environment in which students feel safe "to bumble around.”

During their time in a BSW or MSW program, students create professional and social networks with peers and faculty members, and these networks are viewed as vital to lifelong learning. Social work programs provide an environment rich with networks that support learning and "all of us will take for the rest of our lives." Student participants reported that social work education had stimulated lifelong learning by offering new and challenging ideas and theories as well as opportunities to do research on topics that students had not thought about previously. They spoke enthusiastically about ongoing dialogue with faculty members and peers, and maintaining relationships with former instructors as a way of continuing the learning process.

\section{Lifelong Learning in the Workplace}

Focus group participants discussed several aspects of lifelong learning in the workplace environment, including learning from the community and working with students. Sharing information with workplace colleagues and attending conferences to meet licensure requirements for continuing education were also key aspects of workplace learning. Participants described characteristics of workplace cultures that both promote and inhibit lifelong learning. Limited time due to heavy caseloads and other responsibilities was frequently mentioned as a hindrance to ongoing learning in the workplace.

Some participants were thankful that they work in organizations that promote lifelong learning and where other staff are also eager to learn: "I enjoy my career and I enjoy what I do and a lot of that is due to the fact that there is so much opportunity to learn things" 
(field instructor) and "within our agencies, there are a lot of people who just yearn for more information" (field instructor). For field instructors and alumni/practitioners, the presence of social work students in their workplace was viewed as a lifelong learning strategy both for sharing their knowledge and skills with the next generation of social workers, as well as contributing to their own continuing learning: "training people who are new and excited about the field helps me to feel excited again," and "being a field instructor also helps me to maintain my edge” (alumnus/practitioner). Practicing social workers agreed that finding a supervisor who supports lifelong learning is essential in large bureaucratic organizations. An alumnus/practitioner cited the positive impact of his workplace supervision:

Every time we would have supervision, I literally would have five new articles that I had to read and have to be done and talked about and discussed at the next supervision or the next group...I've been very grateful and lucky that both of the agencies...have been really, really strong on continuing learning because they know that is what keeps people going.

Participants referred to lifelong learning as an attitude or frame of mind of openness to learning in the workplace and in busy or stressful workplaces, such as public child welfare, as an antidote to burnout, as exemplified by one participant:

The work we do is so taxing, so learning different ways to try to alleviate - there is such high burnout, as we all know, and stress in all the work that we do, so just really trying to learn ways... to eliminate some of that stress because there is so much responsibility. (field instructor)

Limited time in the workplace may prevent practitioners from digesting new information and continuing their learning. Several participants identified challenges in their busy work environments related to time and organizational pressures: "I think some barriers for me are sometimes lack of time to actually sit down and get the information I need, particularly if things are in a crisis mode" (field instructor) and "I have to literally spend my weekends if I want to gather information on anything” (alumnus/practitioner). As noted by a participant in public child welfare, other concerns such as large caseloads, overwork, and fear of making a mistake may inhibit learning: "People intend to use strengths, but because of those fears, really do limit them" (field instructor). Students in field placement discussed their disappointment in discovering the lack of a learning culture in some social work practice settings:

Sometimes the system works against us to actually be prepared and to get the knowledge. 'Oops, sorry, in and out, sorry, we are in fast-food social work here.' There are not too many jobs unless you are in academia where they are going to say, 'yes, take the time, do some research, we really care about your learning'. (MSW student)

\section{Discussion}

Participants in this study expressed a range of personal motivations for continuing learning from embracing learning as a way of life characterized by curiosity, engagement, and excitement to a passion for critical thinking that compels them to continually learn 
about the political context of their work in order to improve advocacy for clients. Participants described how their lifelong learning stance strengthened their practice and engaged them more fully in their work. Participants' definitions of lifelong learning reflected those reported in the literature (e.g., Billet, 2010; Bolhuis, 2003; Cournoyer \& Stanley, 2002; Dunlap \& Grabinger, 2003; Frost, 2001; Gustavsson, 2002) and included three dimensions: psychological, related to personal characteristics of curiosity and humility; organizational or contextual factors that affect the availability of opportunities for learning and applying new learning; and thirdly, the professional need to continually update their expertise and competence in order to better serve clients. Participants discussed the environmental contexts that supported and contributed to their learning, particularly their social work program and workplace.

The primary limitations associated with the study are the small convenience sample derived from self-selected, non-representative social workers and students associated with an individual school of social work. The self-selection process is likely to have resulted in a sample of participants that are more engaged and enthusiastic about lifelong learning than others. While the research team took steps to assure the trustworthiness of findings, we also recognize that researcher biases in framing the questions, conducting focus groups, and analyzing data may have inadvertently influenced our results. Despite these limitations, we believe that the study yielded a useful preliminary picture of how some social work students, practitioners, and field instructors think about and engage in continuing learning and the conditions that support learning with implications for further research and tentative implications for social work education programs.

\section{Implications for Social Work Education}

Findings highlight the important roles of faculty members as role models who demonstrate a commitment to ongoing learning in their own professional lives, who model the skills of finding learning opportunities and resources, and who share resources with students. Based on findings from this study, social work faculty will need to continually upgrade their technological skills to integrate the wealth of available electronic media into their teaching, which is likely to enhance students' access to information after graduation. As noted by participants, and recognizing that BSW and MSW programs provide only foundations for professional development, instructors need to support students who are highly motivated learners and to inspire students who are not intrinsically curious.

Critical thinking and a social justice orientation emerged as motivations for lifelong learning, and these emphases in social work programs are likely to inspire continued learning. As social work programs engage in competency-based education, the use of portfolios to document student learning and promote the development of learning goals after graduation, holds promise that students will continue to increase their knowledge and improve their skills subsequently (Cournoyer \& Stanley, 2002). Also, understanding that access to scholarly publications and research journals is heavily influenced by affiliation with an academic program or the workplace environment, faculty may consider publishing their work in open access journals, blogs, and other publicly accessible formats in order to support ongoing learning in the field. 
Participants described the benefits of social networks created in their social work program for continuing learning after graduation and throughout their professional careers. For students who are less connected socially, have competing responsibilities and demands on their time, or are less motivated to be self-directed learners, social work faculty are faced with the challenges of facilitating the development of motivation for lifelong learning, assessing students' commitment to career-long learning, and creating the conditions for this to occur. Therefore, instructors are encouraged to increase opportunities and supports for the development of learning networks, particularly for students who are less likely to engage in groups whether because of personality or cultural factors, time constraints, or other factors. A small number of student participants voiced shame-based motivations for learning which merits further investigation. Even if this is a challenge experienced by only a few students, we suggest that faculty normalize this response and create learning environments in which all students can feel safe when disclosing their lack of knowledge or experience.

\section{Implications for Social Service Organizations}

Participants reported that busy agency contexts and high caseloads constrain the time available for further learning, resulting in their need to devote their personal time to learning. As noted by participants, a workplace's low tolerance for risk slows adaption of new information into practice, limiting the opportunities for staff to share innovative practices they have learned with their colleagues. Conversely, even though resources are limited in most social service organizations, supporting opportunities for ongoing learning may provide benefits in increasing skills, re-energizing staff, reducing burnout, and improving services to underserved client groups. The roles of supervisors in supporting learning were emphasized as well as the benefits of offering field placements to students as ways of introducing new ideas into the work environment.

\section{Implications for Future Research}

While this study was exploratory and based in one school of social work, it provides a beginning understanding of social workers' and social work students' perspectives on lifelong learning, and led to the identification of further questions for future research. For example, how are schools of social work and specific instructors preparing students to have the attributes, motivations, and skills to be lifelong learners? Our sample was self-selected and expressed their passion for lifelong learning, but a challenge to be explored is how to motivate students who are less oriented to lifelong learning to continually upgrade their knowledge and skills.

Explorations are needed to identify what curricula and teaching modalities are best suited to facilitating the skills for ongoing learning. The use of portfolios is gaining popularity in social work programs but little is known about whether this approach promotes ongoing learning. While not specific to social work, one study indicated positive outcomes of the use of e-portfolios to foster integrative knowledge development (Peet et al., 2011), a topic that merits further research in social work. Social networks were also appreciated for sharing new information and ideas, which led the research team to speculate about how learning groups and learning communities are best created and used in both 
schools and the workplace. We recommend further research to explore the phenomenon of social networks as important media for sharing knowledge and learning resources, and to understand how social workers who are less well-connected to networks gain the expertise they need.

Though many social service organizations provide or encourage access to continuing education, others may stifle employees' desires for learning opportunities with demanding workloads. Participants expressed concern about the "fast food" climate in some busy agencies and reported thinking of their ongoing learning as "subversive" which raises questions about how social service organizations can best serve the community and achieve their mission while also promoting lifelong learning. Research has shown that learning organizations are highly effective (Senge, 2006), providing support for organizational leaders to embrace lifelong learning. Further research is needed to understand costeffective strategies for promoting learning opportunities to continually enhance staff skills while also assuring that necessary work is completed. Additionally, research is needed to understand the developmental trajectories of lifelong learners across social work fields of practice and areas of expertise. Finally, studies are needed to explore the links between continuing learning and social work practice. Specifically, in what ways does ongoing learning improve the quality, responsiveness, and effectiveness of social work services?

\section{Conclusion}

The imperative to remain engaged in continuing learning is central for the social work profession to be effective in delivering interventions that are relevant to community needs and responsive to the cultural groups served by social workers. While small in scope and exploratory in design, this study provides a preliminary examination of the perspectives of social workers and social work students in one community on lifelong learning. Participants in this study addressed the psychological, organizational, and professional dimensions of lifelong learning and expressed eagerness to learn, appreciation for the learning opportunities they had received or sought for themselves, and some frustration about limitations in access to scholarly resources and the time needed for learning on the job. Rapid technological change is creating new pathways for learning and personal social networks are a valuable medium for communication among social workers. Faculty members have key roles in promoting and supporting lifelong learning, as role models, social connectors, inspiration, and as springboards for lifetimes of learning and growing. Palmer (1999) has articulated the faculty role well as it applies to social work education:

...This profound human transaction called teaching and learning-is not just about getting information or getting a job. Education is about healing and wholeness. It is about empowerment, liberation, transcendence, about renewing the vitality of life. It is about finding and claiming ourselves and our place in the world. (p.18)

Lifelong learning may be one mechanism for living out this philosophy. 


\section{References}

Billet, S. (2010). The perils of confusing lifelong learning with lifelong education. International Journal of Lifelong Education, 29(4), 401-413. doi: http://dx.doi.org/10.1080/02601370.2010.488803

Bolhuis, S. (2003). Towards process-oriented teaching for self-directed learning: A multidimensional perspective. Learning and Instruction, 13(3), 327-347. doi: http://dx.doi.org/10.1016/S0959-4752(02)00008-7

Charmaz, K. (2005). Grounded theory in the $21^{\text {st }}$ century: Applications for advancing social justice studies. In N. K. Denzin \& Y. S. Lincoln (Eds.), The Sage handbook of qualitative research ( $3^{\text {rd }}$ ed., pp. 507-535). Thousand Oaks, CA: Sage.

Council on Social Work Education [CSWE]. (2014). Draft 3 of the 2015 Educational Policy and Accreditation Standards (EPAS). Alexandria, VA: Author. Retrieved from: http://www.cswe.org/File.aspx?id=76675

Cournoyer, B. R., \& Stanley, M. J. (2002). The social work portfolio: Planning, assessing, and documenting lifelong learning in a dynamic profession. Pacific Grove, CA: Brooks/Cole.

Creswell, J. W. (2013). Qualitative inquiry \& research design ( $3^{\text {rd }}$ ed.). Thousand Oaks, CA: Sage.

Daley, B. J. (2001). Learning and professional practice: A study of four professions. Adult Education Quarterly, 52(1), 39-54. doi: http://dx.doi.org/10.1177/074171360105200104

Dunlap, J. C., \& Grabinger, S. (2003). Preparing students for lifelong learning: A review of instructional features and teaching methodologies. Performance Improvement Quarterly, 16(2), 6-25. doi: http://dx.doi.org/10.1111/j.1937-8327.2003.tb00276.x

Frost, N. (2001). Professionalism, change, and the politics of learning. Studies in Continuing Education, 23(1), 5-17. doi: http://dx.doi.org/10.1080/01580370120043

Gira, E. C., Kessler, M., \& Poertner, J. (2004). Influencing social workers to use research evidence in practice: Lessons from medicine and the allied health professions. Research on Social Work Practice, 14(2), 68-79. doi: http://dx.doi.org/10.1177/1049731503262128

Glaser, B., \& Strauss, A. (1967). The discovery of grounded theory. Chicago: Aldine.

Gustavsson, B. (2002). What do we mean by lifelong learning and knowledge? International Journal of Lifelong Learning, 21(1), 13-23. doi: http://dx.doi.org/10.1080/02601370110099489

Kitzinger, J. (1994). The methodology of focus groups: The importance of interaction between research participants. Sociology of Health and Illness, 16(1), 103-121. doi: http://dx.doi.org/10.1111/1467-9566.ep11347023 
Lam, O. B., Wong, D. K. P., Hui, S. K., Lee, F. W. L., \& Chan, E. K. L. (2006). Preparing social workers to be lifelong learners: Use of problem-based learning as a training component in the social work curriculum. Journal of Teaching in Social Work, 26(3/4), 103-119. doi: http://dx.doi.org/10.1300/J067v26n03 07

Morse, J. M. (1994). "Emerging from the data”: The cognitive processes of analysis in qualitative inquiry. In J. M. Morse (Ed.), Critical issues in qualitative research methods (pp. 23-43). Thousand Oaks, CA: Sage.

Nissan, L., Pendell, K., Jivanjee, P., \& Goodluck, C. (2014). Lifelong learning in social work education: A review of the literature and implications for the future. Journal of Teaching in Social Work, 34(4), 384-400. doi: http://dx.doi.org/10.1080/08841233.2014.936577

Padgett, D. (2008). Qualitative methods in social work research (2nd ed.). Thousand Oaks, CA: Sage.

Palmer, P. J. (1999). The grace of great things: Reclaiming the sacred in knowing, teaching, and learning. In S. Glazer (Ed.), The heart of learning: Spirituality in education (pp. 15-32). New York: Penguin.

Parrish, D. E., \& Rubin, A. (2011). An effective model for continuing education training in evidence-based practice. Research on Social Work Practice, 21(1), 77-87. doi: http://dx.doi.org/10.1177/1049731509359187

Peet, M., Lonn, S., Gurin, P., Boyer, P., Matney, M., Marra, T., Taylor, S. H., \& Daley, A. (2011). Fostering integrative knowledge through ePortfolios. International Journal of ePortfolio, 1(1), 11-31.

Petracchi, H., \& Zastrow, C. (2010a). Suggestions for utilizing the 2008 EPAS in CSWE accredited Baccalaureate and Masters curriculums -Reflections from the field, Part 1: The explicit curriculum. Journal of Teaching in Social Work, 30(2), 125-146. doi: http://dx.doi.org/10.1080/08841231003704761

Petracchi, H. E., \& Zastrow, C. (2010b). Suggestions for utilizing the 2008 EPAS in CSWE-accredited Baccalaureate and Masters curriculums - Reflections from the field, Part 2: The implicit curriculum. Journal of Teaching in Social Work, 30(4), 357-366. doi: http://dx.doi.org/10.1080/08841233.2010.515928

Polkinghorne, D. (2007). Validity issues in narrative research. Qualitative Inquiry, 13, 471-486. doi: http://dx.doi.org/10.1177/1077800406297670

Senge, P. (2006). The fifth discipline: The art and practice of the learning organization. NY: Random House/Doubleday.

Smith, C. A., Cohen-Callow, A., Dia, D. A., Bliss, D. L., Gantt, A., Cornelius, L. J., \& Harrington, D. (2006). Staying current in a changing profession: Evaluating perceived change resulting from continuing professional education. Journal of Social Work Education, 42(3), 465-482. doi: http://dx.doi.org/10.5175/JSWE.2006.042310002 
Wharton, T. C., \& Bolland, K. A. (2012). Practitioner perspectives on evidence-based practice. Families in Society, 93(3), 1-8. doi: http://dx.doi.org/10.1606/1044$\underline{3894.4220}$

\section{Author note}

Address correspondence to: Pauline Jivanjee, PhD, MSW, The School of Social Work, Portland State University, 1800 SW 6th Ave., Ste. 600, Portland, OR 97201. Email:

jivanjee@pdx.edu 